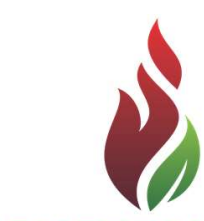

SUSTENERE

Publishing Corporation

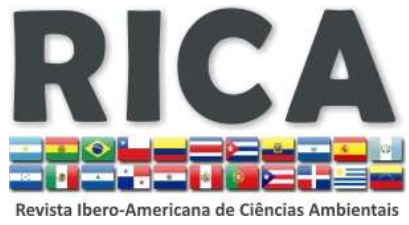

Journals Homepage:

www.sustenere.co/journals

\section{RESPONSABILIDADE SOCIAL DE UM GRANDE BANCO DE VAREJO BRASILEIRO}

\section{RESUMO}

O presente trabalho apresenta o posicionamento do Banco do Brasil S.A. frente à questão da responsabilidade social. O Balanço Social ou Relatório de Sustentabilidade é utilizado como ferramenta de análise uma vez que foi criado com o objetivo de evidenciar a atuação das empresas sob a ótica social. O delineamento da pesquisa configura-se como descritivo na medida em que apresenta as características de informações evidenciadas nos Balanços Sociais da instituição financeira objeto de estudo. Para coleta de dados foram selecionados sete indicadores dos Balanços Sociais do Banco do Brasil S.A., referentes ao período de 1997 a 2006. Os resultados mostram o aumento dos investimentos na área social, tanto em projetos de combate a fome quanto em benefícios para os funcionários. Os avanços observados nos estudos denotam serem frutos da conscientização das pessoas da necessidade de busca de um crescimento sustentável que permite a inclusão social e maiores oportunidades para todos.

PALAVRAS-CHAVES: Balanço Social; Sustentabilidade; Responsabilidade Social; Banco do Brasil; Demonstração do Valor Adicionado.

\section{SOCIAL RESPONSIBILITY OF A LARGE BRAZILIAN RETAIL BANK}

\section{ABSTRACT}

This paper presents the position of the Bank of Brazil against the issue of social responsibility. The Social and Sustainability Report is used as a tool of analysis since it was created in order to demonstrate the performance of companies in the social standpoint. The research design appears as descriptive as it has the characteristics of information shown by the financial institution balance sheets Social object of study. For data collection were selected seven indicators of Social Balances Bank of Brazil SA, for the period 1997 to 2006. The results show an increase in social investments, both in projects to fight hunger and provide benefits to employees. The advances made in studies of fruit denote be awareness of people's need to search for a sustainable growth that allows social inclusion and increased opportunities for all.

KEYWORDS: Social Report; Sustainability; Social Responsibility; Banco do Brazil; Statement of Value Added.
Revista Ibero-Americana de

Ciências Ambientais, Aquidabã, v.6, n.2, Jun, Jul, Ago, Set, Out, Nov 2015.

ISSN 2179-6858

\section{SECTION: Articles}

TOPIC: Indicadores de

Sustentabilidade

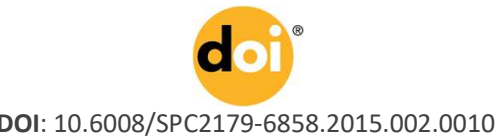

Helton Cristian De Paula Universidade Federal de Ouro Preto, Brasil http://lattes.cnpq.br/3828530957549950 heltoncristian@gmail.com

Received: $27 / 02 / 2015$

Approved: 14/10/2015

Reviewed anonymously in the process of blind peer.

\section{Referencing this:}

PAULA, H. C.. Responsabilidade social de um grande banco de varejo brasileiro. Revista Ibero-Americana de Ciências Ambientais, Aquidabã, v.6, n.2, p.144-158, 2015. DOI: $h$ ttp: //dx.doi.orq/10.6008/SPC2179 $\underline{6858.2015 .002 .0010}$ 


\section{INTRODUÇÃO}

O Ministério do Meio Ambiente (2004) afirma que 'o crescimento econômico é uma condição necessária, mas não suficiente, para o desenvolvimento sustentável, o qual pressupõe um processo de inclusão social com uma vasta gama de oportunidades e opções para as pessoas'. Tal afirmação apresenta um tema frequentemente abordado na mídia e comum na agenda de grande parte dos chefes de estado nos últimos anos, a preocupação com o desenvolvimento sustentável. Por várias décadas, principalmente após a Revolução Industrial, a grande preocupação das companhias, das pessoas e principalmente das nações era predominantemente o crescimento econômico. Acreditava-se que crescimento econômico era sinal de prosperidade, já que trazia riquezas para todos. Porém, a crise de 1929 foi um duro golpe nesse tipo de crença. A grande depressão, como ficou conhecido esse período da história, aconteceu em função principalmente do volume de produção conquistado com os avanços da Revolução Industrial. Porém, não foi somente a quantidade de oferta de bens, pois esse fato isolado possivelmente não provocaria uma crise de tais proporções.

Um fator que contribuiu para a crise foi justamente à disponibilidade de renda. Diante da grande quantidade de oferta de bens, as pessoas não tinham dinheiro para comprá-los, o que provocou problemas financeiros nas empresas pela ausência de vendas para fazer frente aos compromissos assumidos. Esse cenário agravou-se a cada dia, culminando com a quebra da Bolsa de Nova York em 1929 (KEYNES, 1992). A grande depressão levou a reflexão e a reavaliação de vários padrões de comportamento e crenças existentes. Um dos questionamentos foi que o crescimento econômico era sinal de prosperidade e sucesso. A questão econômica ainda é um tema que gera apreensão de todos os países do mundo, porém, agora existe a preocupação não somente com desenvolvimento econômico, mas também com desenvolvimento sustentável. O desenvolvimento sustentável remete a um conceito de duração, de continuidade. Porém, o termo é utilizado não somente para definir um ciclo de desenvolvimento duradouro, como também para aquele que gere benefícios para várias pessoas. Logo a expressão pode ser aplicada no sentido de caracterizar um período de evolução que seja proveitoso para muitos, e que seja contínuo a ponto de tornar-se um ciclo vicioso (SACHS, 1993).

Entende-se que a amplitude do conceito desenvolvimento sustentável envolve o período no qual há crescimento econômico concomitante ao processo de inclusão social, oferecendo oportunidade e opções para o maior número possível de pessoas. A tarefa de promover a inclusão social tem sido desempenhada por diversas organizações, principalmente aquelas criadas especificamente com esse fim. Porém, a cobrança para que empresas com fins lucrativos façam investimentos nesse tipo de projeto é crescente, e funciona como uma forma de contrapartida pelos resultados que a própria sociedade lhe proporciona. Diante desse contexto, é importante verificar como as empresas têm se posicionado diante do tema, se está havendo contrapartida de seus resultados para a sociedade e como ocorre esse processo. Assim, o objetivo do trabalho 
consiste em verificar o posicionamento do Banco do Brasil S.A. frente à questão da responsabilidade social.

\section{METODOLOGIA}

O delineamento da pesquisa configura-se como descritivo na medida em que apresenta as características de informações evidenciadas nos Balanços Sociais da instituição financeira objeto de estudo. E ainda, exploratório por abordar um tema cujos conhecimentos ainda são relativamente incipientes, portanto, carente de análises mais detalhadas. Pesquisas exploratórias são desenvolvidas com o objetivo de proporcionar visão geral, de tipo aproximativo, acerca de determinado fato. Este tipo de pesquisa é realizado especialmente de acordo com Vergara (1998, p.45), quando se tem uma 'área na qual há pouco conhecimento acumulado e sistematizado por sua natureza de sondagem, não comporta hipóteses que, todavia, poderão surgir durante ou ao final da pesquisa'.

Para coleta de dados foram utilizados os Balanços Sociais do Banco do Brasil S.A. publicados no período de 1997 a 2006. A escolha da instituição financeira foi motivada pela importância que a empresa tem em seu segmento de atuação, já que é um dos maiores bancos de varejo do país, segundo informações amplamente difundidas na mídia e confirmadas pela Federação Brasileira de Bancos (FEBRABAN). Outro fator levado em consideração foi o fato de ser uma sociedade de economia mista. Apesar de ser uma empresa cujo controle acionário pertence à União, tem ações negociadas na Bolsa de Valores de São Paulo (BOVESPA), listadas no segmento NOVO MERCADO, que congrega companhias com nível de Governança Corporativa diferenciada.

Além disso, trata-se de um segmento de atuação muito suscetível a influência da opinião pública, a indústria financeira. Provavelmente esse setor é alvo de maior interesse da população porque impacta diariamente na vida de cada um, fornecendo serviços de intermediação financeira, empréstimos e aplicações, além de ter auferido nos últimos anos lucros expressivos, o que alimenta discussões acerca de sobretaxas e sistemas mais rígidos de regulação de mercado. Outro fator importante é o fato da indústria financeira ser grande responsável por incentivar o desenvolvimento das nações, através principalmente da intermediação financeira, viabilizando investimento e planos de expansão de companhias, contribuindo para criar condições para que ocorra o desejado crescimento econômico discutido no início desse trabalho.

Para análise dos dados foram selecionados sete indicadores econômicos e sociais pela representatividade no Balanço Social e variações significativas ao longo do período analisado: Receita Líquida; Resultado Operacional; Participação nos Lucros ou Resultados; Folha de Pagamentos; Encargos Sociais; Combate a Fome e a Segurança Alimentar e Relação entre a maior e menor remuneração paga pela empresa. A partir desses indicadores faz-se uma analise inferencial do comportamento histórico das ações do Banco do Brasil voltadas à área social. 
Para facilitar a análise dos dados, os cinco primeiros indicadores foram apresentados em percentuais em função do ano de 1997 (ano base). Logo, para calcular o indicador Receita Líquida, para o ano de 1998, basta dividir o valor evidenciado no Balanço Social para esse indicador nesse ano, pelo valor do mesmo indicador referente ao ano de 1997. Do resultado subtrai-se 1 (um) e multiplica-se por 100 (cem), encontrando então a variação percentual em função do ano base (1997). O mesmo procedimento deve ser aplicado para os demais anos. Dessa forma, esses cinco indicadores terão valor 0 (zero) em 1997.

Quanto ao sexto indicador, Combate a Fome e a Segurança Alimentar, em função de não haver investimentos até o ano de 2002, optou-se por analisar a representatividade do item em relação a Receita Líquida. Desse modo, o valor evidenciado no Balanço Social para Combate a Fome e a Segurança Alimentar foi dividido pelo valor divulgado a título de Receita Líquida, e o resultado foi multiplicado por 100 (cem) indicando desse modo qual percentual da Receita foi aplicado nesse tipo de projeto. O último item foi demonstrado de forma quantitativa, tal como apresentando no Relatório de Sustentabilidade. Acredita-se que tal número já oferece possibilidade de análise, uma vez que representa a razão entre a maior e a menor remuneração paga pela empresa, ou seja, quantas vezes maior é a remuneração do funcionário que recebe mais em função daquele que recebe menos.

\section{REVISÃO TEÓRICA}

\section{Responsabilidade Social}

Não se sabe onde surgiu o termo Responsabilidade Social tampouco quem o utilizou pela primeira vez. Supõe-se que foi utilizado pioneiramente em meados de 1950, nos Estados Unidos ou na Europa. Nessa época, a preocupação era centrada na influência excessiva dos negócios na sociedade, principalmente nas consequências das atividades empresariais. Duarte e Dias (1986) afirmam que segundo Howard Bowen, cuja obra é um marco no campo da Responsabilidade Social da Empresa, as primeiras manifestações desta ideia surgiram no início do século, em 1906, com trabalhos de Charles Eliot, em 1907 com Arthur Hakley e com Jonh Clark em 1916. Tais ideias, porém, não tiveram maior aceitação nos meios acadêmicos e empresariais, onde deviam soar - considerando a época - como heresias socialistas. Em 1923, o inglês Oliver Sheldon defendeu a inclusão de outros objetivos para as empresas além do lucro dos acionistas, porém sem lograr êxito.

O ano de 1929 foi extremamente turbulento principalmente sob a ótica econômica, devido à quebra da Bolsa de Nova York. Esse fato levou a profundas reflexões e a revisão de modelos e padrões. Talvez em função disso, em 1942, um manifesto subscrito por 120 industriais ingleses resgatou a ideia de Sheldon. Duarte e Dias (1986) expõem que em 1953 nos Estados Unidos foi publicada uma das primeiras obras analisando o tema, intitulada Social Responsibilities of the 
Businessman, de Howard Bowen. Esse foi um marco no estudo do tema, já que a partir desse trabalho o assunto passou a ser discutido por empresários e acadêmicos norte americanos.

Segundo Borger (2001), na década de 1960 os estudos buscaram consolidar o tema e delimitar um conceito para responsabilidade social empresarial, norteado pela idéia de que a responsabilidade das empresas ultrapassa o objetivo de gerar lucros para seus acionistas. Apesar dos esforços empreendidos desde a década de 60, ainda hoje não há consenso sobre o conceito de responsabilidade social. Srour (2000) o define como tentativa de compatibilizar os interesses e exigências das organizações e dos stakeholders, remetendo a uma cidadania organizacional no que concerne ao âmbito interno da empresa e o âmbito externo à implementação de direitos sociais. Ferrell (2001) conceitua responsabilidade social como uma espécie de obrigação que a empresa assume junto à sociedade com a única finalidade de maximizar os efeitos positivos e minimizar os impactos negativos gerados por ela.

Duarte e Dias (1986) e Tinoco (2001) afirmam que a sociedade civil tem papel fundamental para definir a obrigação que será assumida pelas empresas, já que através de suas diversas formas de organização, como Universidades, igrejas e fundações, consegue exercer influência sobre os empresários. Destacam também que movimentos para reivindicar essas ações diversas vezes ganharam as ruas, porém nem sempre de forma pacífica. Para Tinoco (2001) alguns investidores éticos utilizaram como armas as participações que detinham nas grandes empresas. Nas assembleias gerais de acionistas, fizeram pressão sobre os conselhos de administração das companhias para reorientar suas políticas, no sentido de atender a essa demanda social. Também os acionistas minoritários se organizaram procurando apoio de especialistas como jornalistas, professores universitários, contadores, economistas e pesquisadores de grandes instituições para pressionar as companhias.

A fonte de financiamento mais antiga de projetos na área de responsabilidade social é a cobrança de tributos, uma vez que uma das funções dos governos é garantir melhores condições para seus cidadãos. Contudo, devido às complexidades criadas pela sociedade moderna, o recolhimento de impostos e os projetos estatais se mostraram ineficientes para suprir todas as necessidades (BORGER, 2001). Com a intensificação da concorrência, e o aumento das pressões populares, os projetos na área social começaram a aflorar e tornaram-se peças de marketing, já que eram utilizados como mais um argumento de venda e de valorização da marca, buscando transmitir a imagem de empresa responsável. Atualmente os projetos sociais deixaram de ser um apelo adicional de marketing em resposta a uma pressão popular, e tornou-se uma das grandes preocupações das empresas e seus gestores. Tal importância encontra fundamento em estudos realizados pelo Centro de Estudos em Administração do Terceiro Setor (CEATS) da USP em 2002. Os estudos demonstraram que o consumidor está disposto a pagar mais por produtos de empresas socialmente responsáveis. Portanto, em época de concorrência acirrada, qualquer oportunidade de aumentar a margem dos produtos e consequentemente viabilizar aumento de lucros é alvo de interesse de gestores das companhias. 
A importância dada ao tema Responsabilidade Social foi confirmada no Brasil em 1998, quando foi fundado o Instituto Ethos de Empresas e Responsabilidade Social, cuja função é de facilitador e integrador de fontes de recursos (empresas) e consumidores de recursos (projetos sociais). A atuação dessa organização é pautada por princípios e valores éticos, além do objetivo de contribuir para o desenvolvimento social, econômico e ambientalmente sustentável.

Importante destacar que esse é um movimento mundial, e assim como o exemplo brasileiro do Instituto Ethos existe similares em diversos outros países. Tal fenômeno reforça a hipótese de que a responsabilidade social adquiriu papel de destaque nas estratégias de atuação das empresas, principalmente aquelas que desejam atuar em mercados onde os consumidores são mais exigentes. A partir dessa constatação, surge a necessidade de desenvolver instrumentos para nortear e mensurar a intervenção das empresas nesse campo, justamente o objeto de discussão do próximo tópico.

\section{Caracterização do Balanço Social}

O Balanço Social, também conhecido como relatório de sustentabilidade é um demonstrativo cujo objetivo é evidenciar informações sociais e ambientais das organizações. Contempla informações ambientais, econômicas e sociais, do ponto de vista tanto do usuário interno quanto externo. TINOCO (2001) define o Balanço Social como um instrumento de gestão e de informação que visa evidenciar, da forma mais transparente possível, informações econômicas e sociais, do desempenho das entidades, aos mais diferenciados usuários, entre estes os funcionários.

Um fator importante a ser destacado no conceito do Balanço Social é a inclusão dos funcionários como público-alvo das informações. Esse é um grande avanço, pois é um grupo cuja satisfação tem o poder de afetar os resultados, que até então não havia sido incluído como destinatário direto da informação. Tinoco (2001) coloca ainda que o objetivo do Balanço Social é demonstrar certa realidade econômica e social num determinado período. As informações contidas nesse relatório devem ser diretas, simples e transparentes, permitindo, tanto à comunidade como aos diversos núcleos que interagem com a empresa, avaliá-la, compreendê-la e criticá-la.

Kroetz (2000) afirma que o Balanço Social caracteriza-se como uma ferramenta gerencial que reúne dados qualitativos e quantitativos sobre as relações entidade/ambiente, permitindo identificar problemas e oportunidades, auxiliando a administração na tomada de decisão e na adoção de estratégias empresariais. Assim, apresenta em conjunto com as demais demonstrações contábeis, a solidez da estratégia de sobrevivência e crescimento da organização. Também pode evidenciar, por meio de indicadores, as contribuições à qualidade de vida da população, ampliando assim o grau de confiança da sociedade na entidade e contribuindo para a valorização da marca. 
Apesar de ser um tema amplamente discutido, ainda não se chegou a consenso sobre um padrão de Balanço Social. Existem alguns modelos que são difundidos e tem maior aceitação, contudo, como são modelos, servem somente para nortear a elaboração do Relatório, sendo adaptado por cada companhia de acordo com suas necessidades ou interesses. Embora não haja um padrão rígido e definido, existe certo consenso sobre os principais conjuntos de indicadores a serem contemplados pelos Balanços Sociais.

Carneiro (2002) relata que são dois conjuntos principais de indicadores. O primeiro deles, analisa a Contabilidade sob a ótica sócio-empresarial, onde a empresa é tratada como uma célula social interagindo com o meio no qual está inserida e assumindo responsabilidades com a comunidade e o meio ambiente. O outro contempla indicadores econômicos, organizados na Demonstração de Valor Adicionado (DVA), capazes de evidenciar a geração e distribuição de riquezas. Segundo Tinoco (2001) os indicadores econômicos, organizados na Demonstração de Valor Adicionado auxiliam os administradores na medida em que podem gerar informações para tomada de decisão, além de melhorar a rentabilidade empresarial por meio da manutenção da satisfação dos trabalhadores, fator capaz de afetar os resultados empresariais.

O país pioneiro em adotar a publicação obrigatória do Balanço Social foi à França, que desde 1977 tornou a demonstração obrigatória para todas as empresas com mais de 300 funcionários. Em Portugal, tornou-se obrigatório para todas as empresas a partir de 1985, o mesmo ocorrendo na Bélgica no ano seguinte. Outros países da Europa aderiram à tendência e tornaram também o Relatório obrigatório para suas empresas. O Brasil ainda não aderiu a esse movimento, portanto a evidenciação ainda é voluntária.

O Balanço Social no Brasil tornou-se mais conhecido devido à atuação do sociólogo Hebert de Souza, o 'Betinho'. Foi ele que defendeu a ideia de responsabilidade social das empresas e a divulgação do Balanço social. Em 1997, em parceria com a Petrobrás e o Jornal Gazeta Mercantil lançou uma campanha para divulgar o Relatório de Sustentabilidade sob o argumento que esse seria o primeiro passo para as empresas tornarem-se uma empresa-cidadã. O sociólogo defendeu seus ideais e contribui para aumentar o debate sobre o tema, o que gerou melhorias para diversas pessoas como será constatado nas páginas que seguem. Além disso, recebeu grande destaque devido à adesão posterior de diversas empresas. Logo, com o apoio de uma grande companhia e de um grande jornal, a iniciativa ganhou força e repercussão em âmbito nacional.

Esse foi um marco na história nacional no tema responsabilidade social. A partir disso foram criados modelos e padrões para a publicação. Os mais difundidos são aqueles propostos pela Fundação Instituto de Pesquisas Contábeis, Atuariais e Financeiras (FIPECAFI) da Universidade de São Paulo (USP), que contempla os segmentos laborais, ambientais e a riqueza gerada e modelo proposto pelo Instituto Brasileiro de Análises Econômicas e Sociais (IBASE), que contempla itens relativos ao público interno, ao público externo, meio ambiente e ao corpo funcional. 
Apesar de todos os avanços citados, até hoje não existe uma Lei que obrigue a publicação do Balanço Social, nem mesmo que determine um modelo padrão. Em função disso, conforme expõe Carneiro (2002), a falta de regulamentação de um modelo único de balanço social dificulta a análise comparativa e impede o acesso a informações socioeconômicas nos plano regional e nacional.

A regulamentação do Balanço Social seria um avanço para a área contábil. A evidenciação do Relatório de Sustentabilidade contribuiria para melhorar o processo de comunicação das ações sociais empreendidas pelas organizações ao público e melhoraria o entendimento dos dados, pois atualmente, quando existe disponibilidade de informações dessa natureza, as mesmas não são passíveis de comparação devido a diferenças nos modelos adotados. Não obstante, embora existam todas essas questões a serem resolvidas, o Balanço Social em nenhum momento deixa de ser uma ferramenta que possibilita a análise das informações econômicas, sociais e ambientais de uma companhia, utilidade essa que será empregada para atingir os objetivos propostos por essa pesquisa.

Tinoco (1993) afirma ser necessário gerar relatórios contábeis e sociais que permitam relacionar o desempenho econômico-financeiro ao desempenho operacional e social, bem como relatórios que explicitem a riqueza gerada pela atividade empresarial e sua distribuição entre os agentes de produção. Hendriksen e Breda (1999) expõem que principalmente na Europa, os interesses dos funcionários e do governo são colocados no mesmo nível do interesse dos acionistas, demonstrando a importância que é dada aos diversos grupos nas informações contábeis. Exemplificam tal afirmação citando o caso da França, onde a publicação do Balanço Social é obrigatória e são evidenciadas informações sobre empregos, remuneração, investimentos em proteção à saúde, segurança e treinamento de funcionários, dentre outras. Tais exigências são superiores àquelas encontradas em países como Estados Unidos e Brasil.

Apesar de haver conscientização da necessidade de evidenciação de informações como as contidas no Balanço Social, tal relatório difere das demais Demonstrações Contábeis. As informações contábeis obrigatórias normalmente são orientadas para os acionistas e primam pela análise de indicadores quantitativos e financeiros, diferente do Relatório de Sustentabilidade, que apresenta indicadores sociais qualitativos e quantitativos. Diante dessas diferenças, surgem dúvidas quanto à elaboração e benefícios de sua publicação. De acordo com Kroetz (2000) o Balanço Social é de fato uma demonstração contábil e o contabilista é o responsável pela sua elaboração, visto que a principal fonte dos dados é a escrituração contábil. Sucupira (2001) sugere o uso mais amplo do Balanço Social. Defende a ideia de que apesar de ter sua origem na contabilidade, não deve ser visto apenas como um demonstrativo contábil, mas como uma forma das empresas demonstrarem o cumprimento da sua responsabilidade social, representando um diferencial para aquelas que o adotam.

Ao discorrer sobre os benefícios da publicação, Cappellin e Giuliani (1999) afirmam que em certos países, como Estados Unidos, Bélgica, França, Portugal e Canadá a motivação para 
elaborar o Balanço Social está relacionada à necessidade de um planejamento estratégico de amplo alcance. Assim, para o desenvolvimento de planos, é necessário ter conhecimento das variáveis contábeis e socioculturais. Kroetz (2000) afirma que antes de ser uma demonstração endereçada à sociedade, o Balanço Social é uma ferramenta gerencial. Isso ocorre, pois tal demonstração evidencia informações econômicas, sociais e ambientais que refletem as políticas administrativas e as relações da entidade com o ambiente.

Além desses motivos, Kanuk e Shiffman (citado por FORMENTINI, 2002), afirmam que práticas éticas e socialmente responsáveis são negócios saudáveis que resultam em melhores vendas e que o contrário também é verdadeiro; percepções de falta de responsabilidade social por parte de uma empresa afetam negativamente as decisões de compra do consumidor. A partir das questões levantadas, é possível perceber que as empresas podem ter diversas motivações para publicar o Balanço Social. O fato é que vários usuários, inclusive a sociedade como um todo, demanda a publicação dessas informações. Sendo assim, cabe a empresa avaliar as questões inerentes a evidenciação desse tipo de informação e buscar conciliar seu interesse estratégico com as necessidades de informações dos usuários.

\section{Análise dos Dados}

Para análise dos dados foram selecionados sete indicadores, extraídos do Balanço Social, cujo critério exclusivo de seleção foi à representatividade no conjunto da demonstração e a ocorrência de variação significativa no período analisado. Os itens são: Receita Líquida; Resultado Operacional; Participação nos Lucros ou Resultados; Folha de Pagamentos; Encargos Sociais; Combate a Fome e a Segurança Alimentar; e Relação entre a maior e menor remuneração paga pela empresa. Os indicadores foram calculados conforme descrito na seção Metodologia.

O indicador Receita Líquida demonstra a Receita Líquida da empresa no período analisado. Embora seja um indicador financeiro que é evidenciado em outras Demonstrações Financeiras, é importante para as análises uma vez que sua variação impacta diretamente na disponibilidade de recursos disponíveis para investimentos, tantos de interesse da companhia quanto de cunho social. O Resultado Operacional apresenta a Receita Líquida menos os custos e Despesas Operacionais. É relevante nas analises pertinentes a este trabalho, pois a exemplo da Receita Líquida, influencia diretamente as decisões de investimento.

A Participação nos Lucros ou Resultados evidencia a quantidade de recursos repassados aos funcionários a titulo de distribuição de lucros das operações. É um indicador importante, pois no Brasil não existe regulamentação do montante a ser distribuído, nem mesmo a obrigatoriedade dessa distribuição, portanto reflete estratégia e posicionamento da empresa diante da comunidade, em especial de seus funcionários. A Folha de Pagamento mostra o total 
desembolsado a titulo de pagamento de funcionários. Em conjunto com a participação nos lucros e resultados, fornece indícios de políticas de cargos e salários, e de incentivos e remuneração.

O indicador sobre Encargos Sociais representa o total desembolsado a título de encargos sociais. Teoricamente essa é a parte que a empresa repassa ao governo para que o mesmo realize ações sociais. Um exemplo de encargo social no Brasil é o sistema 'S', composto dentre outros pelo Serviço Nacional da Indústria (SENAI), Serviço Nacional do Comércio (SENAC) e Serviço Brasileiro de Apoio a Pequena e Micro Empresa (SEBRAE). Todos esses órgãos recebem um percentual sobre o salário de cada trabalhador com carteira assinada no país, e são responsáveis por promover ações estruturantes tais como treinamentos, capacitação, e atividades de lazer e cultura.

Quanto ao indicador Combate a Fome e a Segurança Alimentar, reflete o total de recursos destinados ao combate à fome e para projetos que promovam a segurança alimentar. Está engajado em um projeto do governo federal, denominado FOME ZERO, que dentre outras ações redistribui alimentos e instrui a comunidade sob hábitos de alimentação saudáveis dentro do contexto regional e econômico de cada localidade atendida. Quanto a Relação entre a maior e menor remuneração paga pela empresa, apresenta a discrepância entre as remunerações pagas. É um indicador peculiar, porém interessante devido ao tamanho da empresa, que atua em âmbito global e possui milhares de funcionários. Em conjunto com a participação nos lucros ou resultados e a folha de pagamentos bruta aponta indícios de políticas de cargos e salários. No Gráfico 1 apresenta-se o comportamento da Receita Líquida ao longo do período sob análise.

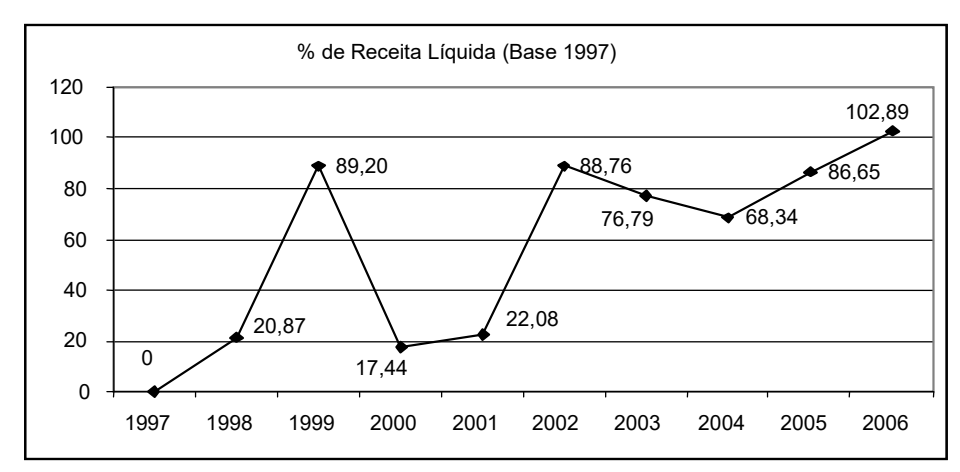

Gráfico 1: Comportamento da Receita Líquida do Banco do Brasil S.A.

Observa-se que apesar de não haver queda de receita no período analisado, os anos de 1999 e 2002 foram responsáveis por picos na Receita, que não se confirmaram nos anos posteriores. A informação mais interessante é obtida por meio da análise de todo o período, no qual se constata crescimento superior a $100 \%$, ou seja, a Receita Líquida da empresa mais que dobrou em uma década. Embora o crescimento seja expressivo e esse seja um indicador que tem grande influência no resultado da empresa, avaliar seus impactos e suas razoes não e tarefa simples dada à complexidade do negocio, principalmente sua suscetibilidade a decisões externas, como taxa de juros e regulamentações. Porém para os propósitos dessa pesquisa, a constatação 
de que a Receita dobrou na década investigada contribui para comparação com a evolução dos demais indicadores analisados.

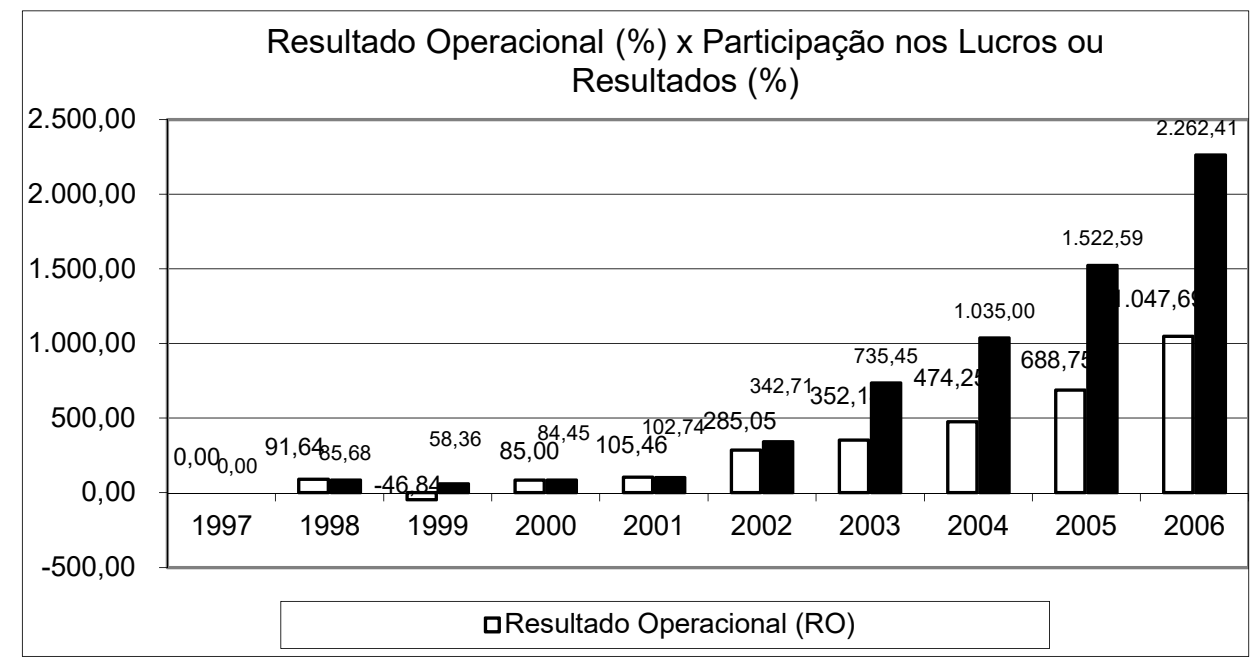

Gráfico 2: Evolução do Resultado Operacional e Participação nos Lucros ou Resultados

O Gráfico 2 apresentam-se o comportamento do Resultado Operacional e da Participação nos Lucros ou Resultados ao longo da série histórica. Optou-se por apresentar esses dois indicadores em conjunto, pois a Participação nos Lucros ou Resultados depende diretamente do Resultado Operacional da empresa. A priori a idéia que se tem é que os dois terão a mesma tendência, seja ela de queda ou alta, o que se pode confirmar com os dados apresentados. Porém, a grande contribuição da comparação entre os dois indicadores e justamente detectar a variação de cada um deles em relação à base de analise.

A única retração no Resultado Operacional foi verificada em 1999, quando foi quase $50 \%$ inferior ao auferido em 1997. Apesar disso, chama atenção à evolução do indicador ao longo da década analisada, já que avançou mais de $1000 \%$, ou seja, aumentou seu valor em mais de dez vezes. Comparativamente a evolução do Resultado Operacional, foi apresentada a Participação nos Lucros ou Resultados. Esse indicador teve um aumento superior a dez vezes já nos primeiros oito anos do período analisado, porém foi nos últimos dois anos da série que teve sua maior variação, chegando ao ano de 2006 vinte e duas vezes maior que a base.

A discrepância entre Resultado Operacional e Participação nos Lucros ou Resultados pode significar maior preocupação da empresa em remunerar melhor seu funcionário, principalmente por meio da participação nos lucros ou resultados, como forma de incentivo para que os colaboradores, normalmente principais responsáveis pelos resultados, se comprometam a buscar sempre mais. No Gráfico 3 apresentam-se os indicadores da Folha de Pagamento Bruta e os Encargos Sociais. Os valores referentes aos Encargos Sociais foram posicionados acima das linhas apresentadas no gráfico, e aqueles referentes à Folha de Pagamento Bruta estão imediatamente abaixo. 


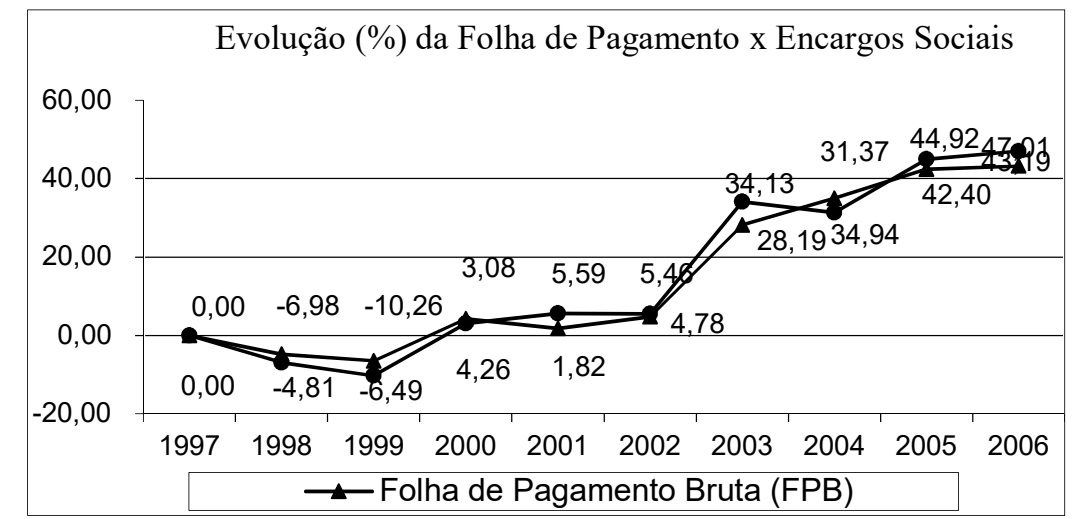

Gráfico 3: Indicadores da Folha de Pagamento Bruta e os Encargos Sociais

A observação dos indicadores indicada tendências parecidas. Tal afirmação encontra respaldo no fato que normalmente os Encargos Sociais são percentuais incidentes sobre a Folha de Pagamento Bruta. Ao comparar o comportamento da Folha de Pagamento Bruta e os Encargos Sociais com a evolução da Receita Líquida pode-se inferir que a evolução da Folha de Pagamento e Encargos Sociais foi bem inferior a da Receita Líquida obtida no mesmo período. Uma das explicações para tal fenômeno substancia-se na automatização e informatização do setor financeiro que possibilitou o aumento de receita sem novas contratações de pessoas. Porém, esse parece ser um tema mais complexo e alvo de diversas pesquisas sobre o impacto da evolução tecnológica nos postos de trabalho.

Uma informação complementar que consta no Balanço Social, todavia, não explorada na pesquisa em função da pequena variação no período de 1997 a 2006 é o numero de trabalhadores. No final de 1997 este número era de 76.387 pessoas enquanto que ao termino de 2006 eram 82.672 pessoas. Apesar da variação em torno de $8 \%$ ao longo da década, tal informação se torna valiosa na complementação da análise do comportamento do gráfico acima. Considerando a variação da Folha de Pagamento Bruta e do número de pessoas empregadas, podem-se identificar melhorias na distribuição de renda, já que um aumento de $8 \%$ dos funcionários foi concomitante ao aumento de $43 \%$ na Folha de Pagamento Bruta. Esse fato novamente dá indícios da política de remuneração da empresa e reforça a ideia de busca por distribuição de renda igualitária. O Combate a Fome e a Segurança Alimentar é apresentado no Gráfico 4 seguir:

O combate à fome foi calculado em função da Receita Líquida do respectivo ano. A primeira constatação na avaliação do gráfico é que até o ano de 2002 não houve investimentos, ou os mesmos foram praticamente irrelevantes em função da Receita Líquida. Tal fato justifica-se pelo controle do Banco do Brasil S.A. pela União, já que foi a partir da mudança de governo em 2002, que foi dada maior ênfase a projetos de combate a fome e de segurança alimentar.

No ano de 2006 foi encontrado o indicador mais expressivo da série, quando chega a representar quase $3 \%$ de toda a Receita Líquida da Empresa. Este percentual denota ser expressivo em se tratando de projetos sociais. Tais investimentos estão alinhados com as ações do Governo Federal no Programa Fome Zero. Talvez esse seja um dos indicadores da influência 
estatal na gestão da empresa, orientado por interesses externos a organização, porém balizando sua estratégia de atuação. O último indicador apresentado é a Relação entre a maior e menor remuneração paga pela empresa, ilustrado no Gráfico 5, conforme abaixo:

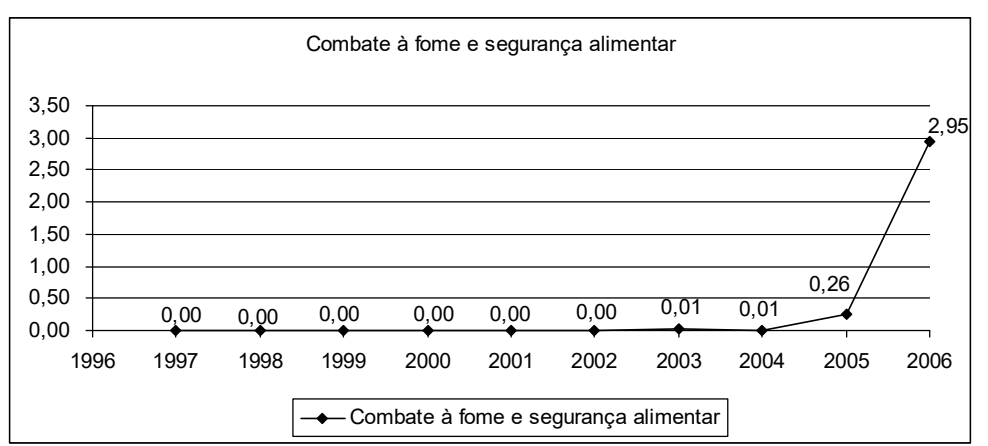

Gráfico 4: Percentual de investimento da Receita Líquida em Combate a fome a segurança alimentar.

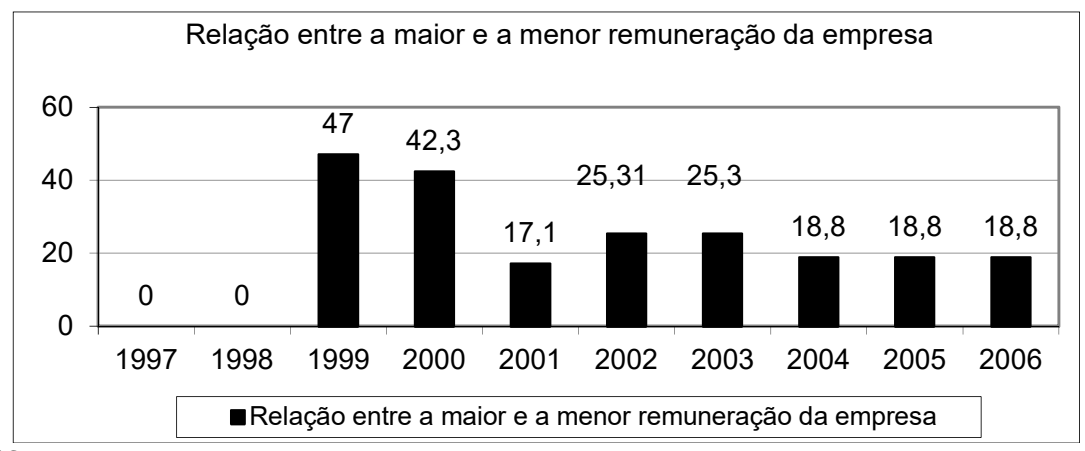

Gráfico 5: Razão entre a maior e menor remuneração paga pela empresa.

O indicador não foi evidenciado pela empresa nos anos de 1997 e 1998. Não foram relatadas causadas para fato, porém, é possível que tenha ocorrido em função da sugestão de algum usuário da informação, visto que os modelos usuais de Balanço Social não apresentam tal informação. O ano de 1999 apresenta que a maior remuneração paga é 47 vezes maior que a menor, indicador expressivo que foi reduzido paulatinamente ao longo do período avaliado, terminando os três anos da série em 18,8 vezes a relação. Esse indicador, em conjunto com a evolução da folha de pagamentos bruta, o número de funcionários e a participação dos lucros demonstra preocupações da instituição em melhorar a distribuição de renda e evidenciam alguns avanços conquistados ao longo do período analisado. Exemplos desses avanços são o aumento da participação dos lucros ou resultados, melhoria da remuneração média (constatada a partir do crescimento de $43 \%$ da folha de pagamento versus $8 \%$ do número de funcionários) e redução das discrepâncias entre as remunerações pagas pela empresa.

\section{CONCLUSÕES}

O Desenvolvimento Sustentável pressupõe também inclusão social. Os dados analisados a partir do Relatório de Sustentabilidade do Banco do Brasil denotam preocupação com os funcionários, responsáveis por planejar e executar estratégias, principalmente as de crescimento e expansão. Embora no Brasil não haja regulamentação quanto à participação de resultados, 
tampouco lei que defina um salário mínimo que atenda as necessidades básicas dos cidadãos, descritas na Constituição Federal da República, é comum na instituição a preocupação em melhorar as condições de trabalho e remuneração de seus colaboradores. Constatou-se com os dados analisados que o Banco do Brasil S.A. mais que dobrou a Receita Líquida na década analisada. Tal constatação confirma a afirmação inicial de que é um setor que desperta grande interesse do público, não só por afetar o cotidiano das pessoas, como também por obter resultados expressivos a cada ano.

Contudo, ao verificar os indicadores sociais, percebe-se o esforço da instituição em contribuir para o desenvolvimento sustentável. No âmbito da sociedade é possível identificar avanços na alocação de recursos para projetos de Combate a Fome e Segurança Alimentar. Tendo em vista o contexto da população brasileira, onde milhões, segundo dados oficiais, vivem abaixo da linha da pobreza, tal iniciativa é de grande importância para criar perspectivas para essas pessoas. Mas é sob o ponto de vista dos funcionários que os avanços conquistados se destacam. É possível identificar que a política da empresa está voltada para melhoria na remuneração e valorização das pessoas dentro do contexto organizacional, verificada através do aumento expressivo da participação do lucro ou resultado se comparado ao resultado operacional, da redução considerável da discrepância entre a maior e menor remuneração dentro da organização e do aumento da remuneração média dentro da companhia.

O Brasil é um dos paises que tem uma das piores distribuições de renda segundo organismos internacionais, o que pode ser verificado principalmente em algumas regiões do país, como o Sertão Nordestino e a região Norte. Desse modo se reconhece que avanços como os demonstrados nesta pesquisa foram alcançados, mas que muitos ainda precisam torna-se realidade para que a situação da maioria das pessoas, não só do povo Brasileiro, como também da população de outros paises do Mundo, de fato seja melhor. Dentro desse contexto o papel das companhias, principalmente as maiores, é fundamental para que os projetos se concretizem. São elas que podem potencializar as ações governamentais, sejam contribuindo com recursos, com mão de obra ou com implementação de projetos que supram lacunas e necessidades da sociedade.

Acredita-se que o presente trabalho cumpriu seu objetivo de evidenciar formas de identificar a atuação das empresas na sociedade, explicitar o surgimento e desenvolvimento da preocupação com o desenvolvimento sustentável, mas principalmente, espera-se que tenha despertado o interesse pelo tema e para sua importância no contexto social. Como sugestões para futuras pesquisas, recomenda-se a avaliação da atuação social de empresas de outros segmentos de atuação ou o foco da avaliação no meio ambiente, questão tida como prioritária nos dias atuais.

\section{REFERÊNCIAS}

ASHLEY, P. A.. Coordenação. Ética e Responsabilidade social nos negócios. São Paulo: Saraiva, 2002. 
BORGER, F. G.. Responsabilidade Social: efeitos da atuação social na dinâmica empresarial. Tese (Doutorado em Administração) - Universidade de São Paulo, São Paulo, 2001.

CAPPELLIN, P.; GIULIANI, M.. Compromisso social no mundo dos negócios. Boletim do Ibase Orçamento e Democracia, v.6, n.11, p.10-11, 1999.

CARNEIRO, C. M. B.. O Balanço Social de Empresas Incentivadas sob Enfoque da Redução de Desigualdade Social: uma investigação no Estado do Ceará. Dissertação (Mestrado em Administração) - Faculdade de Economia e Administração, São Paulo, 2002.

DAVID, A. R.; OTT, E.. Balanço Social: uma análise das informações evidenciadas pelas empresas. In: ENCONTRO ENANPAD. 27. Anais. Atibaia: 2003.

DUARTE, G. D.; DIAS, J. M.. Responsabilidade Social: a empresa hoje. Rio de Janeiro: Livros Técnicos e Científicos, 1986.

FERREL, O. C.; FRAEDRICH J.; FERREL, L.. Ética Empresarial: dilemas, tomadas de decisão e casos. Rio de Janeiro: Reichmann \& Affonso Ed., 2001.

FORMENTINI, M.; OLIVEIRA, T. M.. Ética e Responsabilidade Social: Repensando a comunicação empresarial. Rio Grande do Sul: FAMECOS / PUCRS, 2002.

HENDRIKSEN, E. S.; BREDA, M. F. V.. Teoria da contabilidade. Tradução de Antônio Zoratto Sanvicente. 5 ed. São Paulo: Atlas, 1999.

KEYNES, J. M.. Teoria geral do emprego, do juro e da moeda (General theory of employment, interest and money). São Paulo: Editora Atlas, 1992

KROETZ, C. E. S.. Balanço social: teoria e prática. São Paulo: Atlas, 2000.

SACHS, I.. Estratégias de transição para o século XXI: desenvolvimento e meio ambiente. São Paulo: Fundação do desenvolvimento administrativo, 1993.

MINISTÉRIO DO MEIO AMBIENTE. Agenda 21 Brasileira. Ações Prioritárias. 2 ed. Brasília: Ministério do Meio Ambiente, 2004.

SANTOS, A.. Demonstração do valor adicionado: como elaborar e analisar a DVA. São Paulo: Atlas, 2003.

SROUR, R. H.. Ética Empresarial: posturas responsáveis nos negócios, na política e nas relações pessoais. Rio de Janeiro: Campus, 2000.

SUCUPIRA, J.. Ética nas empresas e balanço social. São Paulo: Atlas, 2001.

TINOCO, J. E. P.. Balanço social e a contabilidade no Brasil. Revista Contabilidade e Finanças. São Paulo, n.9, 1993.

TINOCO, J. E. P.. Balanço social: uma abordagem da transparência e da responsabilidade pública das organizações. São Paulo: Atlas, 2001.

TORRES, C.. Responsabilidade social e transparência. Orçamento e Democracia. Rio de Janeiro, v. 6, n. 10,1998

VERGARA, S. C.. Métodos de pesquisa em administração. São Paulo: Atlas, 1998. 